\title{
UKRAINE'S ECONOMIC SPATIAL STRUCTURES AS A BASIS FOR THE IMPROVEMENT OF TERRITORIAL AND ADMINISTRATIVE ARRANGEMENT
}

\author{
SVITLANA PYSARENKO, MARTA MALSKA
}

Lviv, Ukraine

prosvetka@mail.ru

\begin{abstract}
Keywords: Ukraine, administrative structures
\end{abstract}
\section{INTRODUCTION}

One of the prerequisites of the realization of a Eurointegration strategy for Ukraine is the adaptation of its administrative-territorial division to the requirements of the European Union (EU). This is a long-term policy and it is directed at the improvement of the territorial-administrative system of Ukraine on the basis of merger of the existing administrative units and the creation of spatial units - economic regions of different hierarchical levels corresponding to NUTS1, NUTS2, NUTS3.

The formation of a new system of administrative-territorial division requires the determination of objectively existing spatial units, that is, the use of spatial economic zoning as objective basis for a new administrative-territorial division, taking into account the fact that spatial economic zoning as the objective process, while administrative-territorial division is a subjective process. Practice shows that administrative-territorial system is more inert and it is often an obstacle in the way of formation of objective spatial system of economic regions.

The notion of "national economy" has been defined by Robert Reich in his investigation The Work of Nations as a part of global economy limited by national borders [1,244].

The necessity for the spatial approach to modern national economy is connected with the formation on its basis of an inno-tech network - a system of information-communicative, spatial and motivational connections between its componential and functional subsystems, adapted to global humanitarian economy - attachment strategy.

Chorologic concept is the basis for the formation of modern post-industrial, global information (network) society, the most important feature of which is the substitution of territorial principle of the organization of society by the network principle which is practiced on an ever larger scale.

The term of spatial development by its contents differs from the term of territorial development. In the former case we understand the evolution of the morphology of socio-economic development when space is considered as an order of arrangement of things (Aristotle's line). In the latter - changes 
of functional character in spatial processes are considered, where a territory is a place of arrangement of things (Democritus' line) $(5,34)$.

The necessity for structuredness of space of national economy as the basis of territorial-administrative division has been underlined by a number of researchers. Thus, Jane Jakobs believes that most countries within their national borders are characterized by a combination of very different spatial subsystems $[2,31]$, which taken as a whole form the national economic space.

Spatial approach is combined with genetic approach, which considers socio-economic processes from the point of view of their genesis, dynamics, spatial differences.

Thus, the national economic space is a dynamic system, the parts of which (local regions) are localized on separate territories with appropriate program of development, competitive advantages and synergetic effect.

The investigation of the problem of zoning includes two interrelated approaches - qualitative (systemic) and quantitative (cybernetic). Economic space is characterized by such features as continuity and discreteness and consists of $m$ components - economic regions, formed according to different principles and different hierarchical levels, and $n$ connections between them.

Spatial economic zoning can be regarded as a process of definition of historical, economic, political and social processes in a certain cultural environment, territorial units of which are singled out as parts of spatial structure of society.

An important feature of an economic region as an integral system is spatial stability and inertness, that is, an ability to preserve its structure in the changing environment. An economic region is a system of a complex of factors of production, demands, supply which defines its spatio-temporal structure.

Economic effectiveness of economic regions is defined by two groups of factors. The first is connected with spatial concentration of factors of production, the second consists of the factors which are conditioned by new interrelations and interdependencies between the participants of the process of reproduction in an economic area.

At the same time, it is necessary to underline that economic zoning should take into account congruence, that is, objects of administrative-territorial division should stay integral units.

\section{THE ESSENCE OF INTEGRAL ECONOMIC ZONING AS THE BASIS OF TERRITORIAL- ADMINISTRATIVE SYSTEM OF UKRAINE.}

Modern economic zoning of the national economy of Ukraine which is connected with the development of world economy, processes of globalization, international economic integration may be based on the system of principles (integral, sectoral, historical, ekistical (agglomeration and metropolization), innovation infrastructure, network structures) with account of chorological (spatial) character of their use. Economic zoning, irrespective of the principles of its realization, requires the division of national economy into relatively independent systems, each of which is distinguished by the respective level of social, economic, public integrity and independence.

The aim of economic zoning is the strategy of competitive recovery of the national economy on the basis of balanced long-term spatial socio-economic development. Its realization requires in each economic region agreement of regional and sectoral policies, which directly influences spatial structure of national economy (policy of spatial development).

Depending on the principles at the basis of economic zoning, a spatial system of economic regions, different in genesis and structure, is formed. They include integral economic regions which 
are based on integral principle of zoning. They are the basis of creating NUTS1 regions, and smaller economic regions formed on other principles of zoning as the basis for the definition of NUTS2 and NUTS3.

Integral economic regions define basic directions of socio-economic development of national economy, reflect spatial cooperation, integrity of all the components of national economic and social environment. They may become the carriers of the idea of a new institutional pluralism, the basis of the democratic development of a country.

Such regions must exist and develop according to inter-regional and international division of labour, its cooperation. Their definition requires the transformation of the existing systemic-structural organization of national economy, structuring of national economic space, defining spatial differentiation and concentration of social phenomena.

Integral economic regions are characterized by their discreteness in space, specific structure (polycentric or monocentric), logic of development and functioning.

The Ukrainian legislation has not yet defined the status of integral spatial economic regions, but their formation may favor the adaptation of territorial administrative division of Ukraine to the EU requirements on the way to the realization of its Eurointegration strategy.

Such regions may become analogs of voivodships in Poland, regions in France, Belgium, Great Britain, autonomous regions in Spain, Portugal, provinces in the Netherlands.

The functioning of territorial administrative units of such a level must favor competitive recovery of the national economy on the basis of a more effective use of competitive advantages of respective economic spaces, optimization of their foreign and home relations, entries to new international markets.

Spatio-temporal characteristics of integral economic regions are defined by the level of concentration of socio-economic "masses" (nods) in them as elements of social recreation, formation of growing points in them, "networks" as centers of anticipatory spatial development (centers of activity) which are defined by the concentration of material, service, financial resources.

Integral economic regions define spatial organization of national economy, that is, the location of subjects of economic activity, spatial connections between them and interrelated with them spheres of national economy - spatial interaction, integration of all components of national economic and social spaces.

Thus, an integral economic region is a system of factors of production, demands, supply, which defines its spatial-temporal structure. Such regions are formed on the basis of gravitation theory, the influence of centripetal and centrifugal forces. Centripetal forces create a concentration of subjects of economic activity and a respective zone of their influence, while centrifugal forces define their location in the system of national and world economy.

Economic efficiency of integral economic regions is defined by two groups of factors. The first is connected with spatial concentration of factors of production, the second group comprises the factors which are conditioned by the appearance of interconnections and interrelations between participants of the reproduction process in an economic region.

The formation of integral economic regions may be favored by metropolization, which is characterized by such processes as concentration of different types of activities in the centers of countries - metropolises; the growth of the share of their population in the general population of the country. Such regions become the sources of new ideas, technologies and innovations, generators, engines, stimulators of economic growth. 
The prerequisites for the formation of integrated economic regions on the basis of metropolization may be the following: concentration of scientific potential in large cities, which are the basis of metropolization processes; access to scientific and information infrastructure, research centers, construction industry; existence of favorable conditions for the development of vertical and horizontal integration; formation of the labor market and consumer demand which provide for "economy of scale" for large and small business.

An integral economic region which is formed around a large center-metropolis is characterized by such tendencies as:

- preservation of quasi-static zones near the center which in market economy are formed under the influence of the search for spontaneous equilibrium between demand for and supply of goods and services during decrease of intensity of the development of territories distant from the center of demand;

- continuous or discrete "pressure" on the existing spatial-functional organization of space, which is connected with the desire to obtain the largest possible income from production;

- permanent changes in dynamics and character of demand for and supply of separate groups of goods and services which is the result of changes in demographic and social structure of society. The impulses going from social needs, ecological limitations, technical innovations in the economic region exert pressure on the functional structure of its center;

- growing influence of ecological factor on the location of separate types of activity.

The metropolises which are formed on the basis of cities as centers of gravitational influence on the surrounding environment, according to Eric Lampad, Bert Hozelitz and Wilbur Tompson, may be of three types: productive, economical and performing the controlling function.

In productive metropolises, short distance, size and concentration of potentials of the metropolis provide for the economy of scale and competitive advantages in production costs.

Economic metropolis is an incubator of innovations and entrepreneurship. It favors the interaction of inventors and entrepreneurs decreasing in this way costs for developing and adoption of innovations.

Metropolis of control is the center of decision making, communications and data gathering. The controlling function of a metropolis is based on the concentration within it of a specialized information, communications, central offices of leading companies of the region.

The level of influence between metropolies is directly proportional to the size of their mass (population, economic and innovation potentials, natural, material, financial resources) and inversely proportional to the distance between them.

Such features of metropolises also directly influence economic development of respective integral economic regions. Defining constant rise in the quality of factors of production, support and enlargement of infrastructure, raise in efficiency of social services.

The competitiveness of an integral economic region provides the basis and motivation for its functioning, influences the formation of national market, the place of national economy in the global economic system through:

- interconnections between integral economic regions on the basis of the development of transport, communications, innovation infrastructure;

- adequate functioning of all integral economic regions within national economic system;

- existence of common elements of national economy (currency, monetary, regulatory, foreign policies); 
- regulation of development on the basis of institutional economic mechanisms of cooperation.

In modern conditions, all the types of economic zoning are characterized by the innovation principle, which is based on the formula of "three i's" - innovations, investments, information technologies.

The existing innovation approach to spatial development is based on the theory of convergence and "economic growth." Because of lower dependence of the development of economy on traditional factors of production, competition for the inflow of investments which are the basis for the formation of the model of national economic space development is becoming stronger.

Integral economic zoning as a spatial socio-economic phenomenon has the following features:

- a highly dynamic structure;

- a high level of specialization;

- "diffusion" of social and productive processes in space.

Integral economic zoning is aimed at effective use of endogenous and exogenous factors of the development of the national economy with the aim of raising the level of its competitiveness, providing for the convergence of the national economic space. An integral economic region can be defined as a spatial polystructural heterogeneous system which is defined by integrity; a complex of interrelated subsystems and synergetic effect of their interaction. Its functioning is aimed at megaspace homogenization of socio-economic environment on the basis of the development of spatial functional, genetic interconnections and influence of mobile factors of production, their internationalization.

Structural transformation consists in the restructuring of subsystems of an integral economic region according to the elaborated national strategy which defines general principles and an institutional economic mechanism of its realization. Of special importance is the development of innovation strategies of integral economic regions.

Depending on the level of socio-economic development and competitiveness, supply of resources such regions may develop innovation strategies:

- offensive - consists in its entry on the markets with a brand new product;

- defensive - aimed at keeping the region on the existing segments of the market;

- vanguard - characteristic of spatial integral economic districts with highly innovative segments of market, competitiveness which permits entering new markets;

- imitating, according to which an integral spatial economic district tries to imitate strategies of other regions.

Each strategy is a field of economic activity which is characterized by a systemic integrity of monetary, financial, pricing, investment activity, and can be regarded as an inseparable part of a system of social relations which organically combines economic, social, political, spiritual, psychological, religious, ethnic, domestic and other relations.

International cooperation can be regarded as a factor of additional competitive advantages of an integral economic region which promote the formation of extrovert and introvertive spatial relations and functions. Not defined, but they can favor raising the competitiveness of national economy on the basis of a more effective use of competitive advantages of respective economic spaces, optimization of their foreign and home ties, entry to new international markets. 


\section{MAIN DIRECTIONS OF THE ADAPTATION OF THE STRUCTURE OF ECONOMIC SPACE OF UKRAINE TO THE REOUIREMENTS OF THE EU}

In the conditions of structural transformation, territorial-administrative reform of the regulation of the development of integral economic regions must take into account possible reformation of their functional, technological interrelations and respectively form a new structure of regions.

In 1957-1961, Ukraine made an effort of transfer from branch to territorial principle of management on the basis of formation of administrative economic regions under the control of the Soviet of national economy (sovnarkhoz). Sovnarkhozes according to the principle of their formation may be considered integral economic regions.

Ukraine created 14 sovnarkhozes, and after their merger in 1962-1965 there were 7 of them (Donetsk, Kyiv, Lviv, Podilia, Dnieper, Kharkiv, Black Sea). Each sovnarkhoz consisted of several regions - their territories coincided with the administrative-territorial division.

In the first years of independence (1990-1996) Ukrainian scientists suggested different variants of integral economic zoning. Authors suggested forming from 10 to 6 economic regions on the territory of Ukraine. The main principles of their formation were: socio-historical peculiarities of regions; approximately equal levels of the development of productive, scientific and technical, cultural potentials.

O.I.Shabliy singled out six integral economic regions on the basis of account of processes of agglomeration. These were the following: Western Central, Eastern, South-Eastern, Central-Eastern, Southern with respective centers in Lviv, Kyiv, Donetsk, Kharkiv, Dnipropetrovsk, Odessa.

In the modern conditions there are different schemes of integral economic zoning. The authors of these schemes are O.M.Marych, V.A.Popovkina, F.D.Zastavniy, V.M.Tureyev, S.I.Dorohuntsova, A.M.Fedoryshcheva, P.O.Masliak and P.H.Shyshchenko, V.K.Symonenko and others.

It is necessary to continue the work on the formation of integral economic regions as the basis of transformation of administrative-territorial division. In the modern conditions of development the national economy of Ukraine with the account of the influence of globalization and international integration, that is, the existence of extrovert and introvertive factors of the formation of the strategy of its socio-economic development.

Natural, resource, ecological potentials; geopolitical situation; human capital; innovation and financial resources; the level of capitalization of enterprises, infrastructure play a decisive role in the formation of competitive advantages of integral economic regions which define it as a subject of economy and foreign economic activity. The interdependence between the level of socio-economic development of an integral economic region and the level of the use of competitive advantages define the level of its competitiveness. Integral economic regions must become the main object of regional policy in accordance with the requirements of the EU Common Regional Policy which is based on the realization of neoclassical regional theories combined with theories of concentrated growth.

The EU experience of the solution of problems connected with convergence of its regions is important for Ukraine taking into account Eurointegration strategy of its development. For the first time the rate of convergence of EU member states was calculated by A. Rodriguez-Posse for 110 its European regions for the period from 1977 till 1993 and Armstrong - for 85 regions from 1975 till 1992. They believe that the mean coefficient of regional convergence in the EU member-states in $1977-1993$ was annually $1.2 \%(7$, p.369; 8, p.146)

The aim of the EU Common Regional Policy for the period from 2007 till 2013 is favoring the realization of three tasks: convergence, regional competitiveness and employment as well as territo- 
rial cooperation. The sum of $€ 308.041$ bln will be used for the financing of these three tasks of the EU Common Regional Policy.

The main task of the EU Common Regional Policy for 2007-2013 is convergence, the rise in competitiveness of regions of member-states in accordance with "Community Strategic Guidelines." To this end, the EU member states worked out "Convergence Programs" which define the aims, factors of macroeconomic and regional development of regions (work, productivity, capital).

Provisions concerning Regulations of the EU Common Regional Policy for 2007-2013 include the realization of the policy of convergence on the basis of EU strategic guidelines concerning the leveling of socio-economic development, its growth and the solution of the problem of employment. The policy of convergence is aimed at the solution of problems connected with economic, social and territorial inequalities of regions and faster restructuring of their economy. It is based on the priorities based on Lisbon (economic growth, competitiveness and employment) and Göteborg (environmental protection) principles. Besides, principles and rules concerning cooperation, planning, management, monitoring and control have been worked out on the basis of commitments of the EU member states.

In Ukraine there is a substantial divergence of regions as to the levels of their socio-economic development and connected with it level of competitiveness. In the period from 2007 till 2010 the differentiation of the levels of socio-economic development with the account of the index of gross regional product (GRP) per capita of the regions of Ukraine increased.

Our calculations show that according to this index the regions of Ukraine may be divided into five groups which show deviation from mean state value by:

- $125 \%$ and more - the city of Kyiv, Dnipropetrovsk and Donetsk Regions;

- $10-125 \%$ - Poltava and Zaporizhia Regions

- $76-100 \%$ - Kyiv, Odessa, Luhansk, Mykolayiv Regions and the city of Sevastopol;

- $75-50 \%$ - Lviv, Ivano-Frankivsk, Chernihiv, Kirovohrad, Sumy, Khmelnytsk, Rivne, Volyn', Vinnytsia, Cherkassy, Kherson, Zhytomyr, Zakarpattia Regions and the Autonomous Republic of the Crimea.

The performed cluster analysis of the regions of Ukraine as to the level of their innovation potential let us conclude that its mean level is characteristic of the city of Kyiv only, low - of 9 regions and the lowest - of 15 regions. Most of them belong to the groups of regions in which per capita GRP is less than $75 \%$ of mean state index.

Thus, divergence of regional development is prevalent in Ukraine. The creation of sociallyoriented economic system of the country is impossible with the change of the tendency of the development of its regions to the opposite - convergence of their socio-economic development. In this connection, the experience of the EU Common Regional Policy in the solution of similar problems is important for Ukraine. The development of market environment and market structure corresponding to it will enlarge the possibilities of the use of the experience of the EU Common Regional Policy.

Integral economic regions may become the basis for the realization of such a policy in Ukraine which is directly connected with convergence of national economic space on the basis of:

- provision of the quality of life and raising the well-being of its people;

- balancing the labor market, its quantitative and qualitative structures;

- development of inner national integration, foreign economic ties;

- optimization of inter-regional material, energetic, information, investment relations.

Creation of necessary conditions of the use of competitive advantages in the system of a spatial integration economic region promotes higher competitiveness on the home and foreign markets. 
The policy of coordination, integration and cooperation in the system of national economic space on the basis of integral economic districts includes:

- provision of spatial unity on the basis of convergence, polycentricity of development in the system of economic regions and national economy;

- the use of means of urbanization on the basis of the development of metropolization which must favor the use of endogenous resources - private national capital, direct foreign investments; the development of depressed, rural territories, increased competition among spatial integral economic regions; equal conditions of spatial access on the basis of realization of state programs of the development of transport infrastructure (railroads, highways, ports, airports, telecommunication network);

- better access to information and knowledge first of all for regions with low level of innovation development, the development of technology towns and technological centers in them;

- solution of ecological problems on the basis of coordination of state programs in the sphere of agricultural management, revival of depressed areas which suffered from industrial pollution;

- development and protection of natural resources on the basis of comprehensive use of water resources, including protection of rivers and drainage areas; control of the use of fertilizers in agriculture; definition of natural objects which require protection; preservation of cultural and historical objects within the economic region, and promotion of common (inter-regional) use of objects of tourism;

- joining efforts aimed at the elimination of negative consequences of natural phenomena (earthquakes, floods etc.) within the limits

The cooperation on the level of a spatial integral economic region will favor the adoption of agreed inter-regional decisions on the basis of avoiding contradictions and developing cooperation; economic, social integration of economic regions and national space on the whole, their development on the innovation basis.

Among the instruments of financial stimulation which are used in almost all EU member states and which can be used in Ukraine one can mention investment grants, subsidizing interest rates, tax concessions of subsidies connected with the use of labor force, tax rolls for depreciation, a wider support for the development of business environment in problem regions as assistance which is aimed at improvement of conditions of business activities for all companies of a given region, creation of physical infrastructure combined with "softer" elements of infrastructure. They include the support of information networks, consulting activities, education, scientific research, development works, general (national) programs of economic development.

Special attention should be paid to the activities of agencies of regional development. Their tasks include:

- information and consultations on management of enterprises, attraction of investments, transfer of new technologies;

- provision of financial resources (credits, bank loan guarantees, grants, subventions) for small and middle businesses;

- formation of entrepreneurial infrastructure (technology parks, business incubators, leasing buildings for offices and production). 


\section{REFERENCES}

1. Reich R., 1991, The Work of Nation: Preparing Ourselves for the 21st Century Capitalism, Random House, New York.

2. Jacobs J., 1985, Cities and Wealth of Nations: Principles of Economic Life, Random House, New York.

3. Ohmae K., 1995, The End of the Nation State: The Rise of Regional Economies, Free Press, New York.

4. Zelinsky W., 1980, North America's Vernacular Regions, Annals of the Association of American Geographers, 70, 1, 1-16.

5. Первые сократовские чтения по географии. Географическое пространство: соотношения знания и незнания. - М : РОУ,1993. - С.34-39.

6. Loughlin J., 1996, "Europe of the Regions" and the Federalization of Europe, The Journal of Federalism, 26, 4, 141-162.

7. УССР. Госплан. Материалы по районированию Украины. Секция по районированию. - Харьков, 1923. 
http://rcin.org.pl 